\title{
Assessment of the clinical profile in the children with microcephaly: Random sampling study
}

\author{
Dilipkumar Pabani G. ${ }^{1}$, Rajendra Mehta R. ${ }^{2 *}$, Chandulal Shah P. ${ }^{3}$ \\ DOI: https://doi.org/10.17511/ijpr.2020.i07.09
}

1 Gaurang Dilipkumar Pabani, Assistant Professor, Department of Pediatrics, GMERS Medical College and Civil Hospital, Ahmedabad, Gujrat, India.

2* Rajeshri Rajendra Mehta, Assistant Professor, Department of Pediatrics, Dr. M K Shah Medical College and Research Centre, Ahmedabad, Gujarat, India.

3 Pramod Chandulal Shah, Associate Professor, Department of Pediatrics, Dr. M K Shah Medical College and Research Centre, Ahmedabad, Gujrat, India.

Background and Aim: Primary Microcephaly is also associated with at least 7 gene loci, and 7 single etiologic genes have been identified. Acquired microcephaly can be seen in conditions such as rett, seckel, and angel syndromes and encephalopathy syndrome associated with severe seizure disorders. Hence the study was done to assess the clinical profile of microcephaly in children. Materials and Methods: A total of 104 children were included in the study. The children were divided into different groups as per age distribution. Group A consist of children of age less than 1 year, in group B there were children between age 1 - 5 years, in group $C$ the age of children included was 5 to 10 years and in group $D$ the age of children was more than 10 years. Results: There were 30 children with microcephaly in group A, in group B there were 52 children with microcephaly. For group $C$ there were 20 children with microcephaly and for group $D$ there were 2 children with microcephaly. The maximum numbers of children were in the age group of 1 to 5 years. Conclusion: Microcephaly is a frequent clinical sign which is common in many of the rare diseases, henceforth, as the exact diagnosis is important for counseling the patient and the affected family, regarding the clinical course, possible complication, optimized medical support, and recurrent risk.

Keywords: Microcephaly, Clinical Profile, Children

Corresponding Author

Rajeshri Rajendra Mehta, Assistant Professor, Department of Pediatrics, Dr. M K Shah Medical College and Research Centre, Ahmedabad, Gujarat, India.

Email: rajeshrimehta@yahoo.com

\section{How to Cite this Article}

Pabani GD, Mehta RR, Shah PC. Assessment of the clinical profile in the children with microcephaly: Random sampling study. Pediatric Rev Int J Pediatr Res. $2020 ; 7(7): 375-378$.

Available From

https://pediatrics.medresearch.in/index.php/ijpr/arti cle/view/627
To Browse

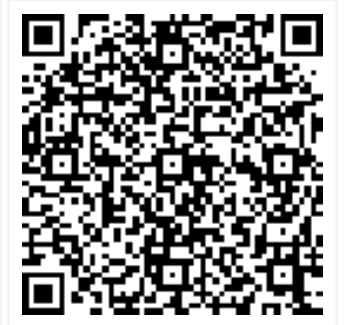

Manuscript Received 2020-09-28

Conflict of Interest No
Review Round 1 2020-10-08

Funding Nil
Review Round 2 2020-10-16

Ethical Approval Yes
Review Round 3

Accepted 2020-10-20

Plagiarism X-checker $5 \%$

(C) 2020 by Gaurang Dilipkumar Pabani, Rajeshri Rajendra Mehta, Pramod Chandulal Shah and Published by Siddharth Health Research and Social Welfare Society. This is an Open Access article licensed under a Creative Commons Attribution 4.0 International License hittps://creativecommons.org/licenses/by/4.0/ unported [CC BY 4.0]. 


\section{Introduction}

Microcephaly is a descriptive term that refers to a cranium that is significantly smaller than the standard for the individual's age and sex [1]. It is a rare neurological condition in which an infant's head is significantly smaller than the heads of other children of the same age and sex. Sometimes detected at birth, microcephaly usually is the result of the brain developing abnormally in the womb or not growing as it should after birth [2]. Microcephaly can be caused by a variety of genetic and environmental factors. Children with microcephaly often have developmental issues. Generally, there's no treatment for microcephaly, but early intervention with supportive therapies, such as speech and occupational therapies, may help enhance your child's development and improve quality of life $[3,4]$.

The causes of microcephaly often remain unknown. In retrospective studies, no etiology was identified in $40-70 \%$ of cases. Mandatory reporting of microcephaly enables a more in-depth assessment of those cases 5. However, there is a wellestablished association between microcephaly and maternal infections, especially those occurring in the first 12 weeks of pregnancy, which can lead to characteristic forms of brain damage. Besides microcephaly, the manifestations include hydrocephalus, cerebral calcifications, ventriculomegaly, cortical migration disorders, white-matter abnormalities, and cerebellar hypoplasia $[6,7]$.

Acquired microcephaly can be seen in conditions such as rett, seckel, and angel syndromes and encephalopathy syndrome associated with severe seizure disorders. Among infectious agents, congenital infections with toxoplasma, rubella, cytomegalovirus (CMV), and herpes simplex virus Type 2 (HSV-2) rank prominently [8]. Various infectious agents like varicella-zoster, group B coxsackievirus, congenital infections with $\mathrm{T}$. pallidum have also been implicated in the etiology of microcephaly with mental retardation [9]. Hence the study was done to assess the clinical profile of microcephaly in children.

\section{Materials and Methods}

The present study was done in the pediatric department of the medical institute. The present study is a cross-sectional study planned on the children from January 2019 to July 2019.
The children presenting with the symptom of microcephaly who attended the outpatient department and also the inpatient department were included in the study. The ethical committee was informed about the study and the ethical clearance certificate was obtained from them.

All the children from age 6 months to 12 years who were satisfied with the presence of microcephaly as a symptom were included in the study. All the children of age more than 12 years and who were not having microcephaly were excluded from the study. The parents were informed about the study and the written informed consent was obtained from them.

A total of 104 children were included in the study. The children were divided into different groups as per age distribution. Group A consist of children of age less than 1 year, in group $B$ there were children between age $1-5$ years, in group $C$ the age of children included was 5 to 10 years and in group $D$ the age of children was more than 10 years.

A questioner was prepared to obtain a detailed history from the parents. Detailed maternal, paternal, and postnatal history were recorded through the preformed questioner. The detailed anthropometric measurements were recorded of all the children.

Head circumference was measured by measuring the tape around the cranial vault to measure the widest part of the forehead and the most prominent part of the occipital area to arrive at the largest possible measurements using the same measuring tape for all the children included in the study.

Clinical profile was assessed using the proforma that included a detailed history, neurological examination, and physical examination. Relevant clinical laboratory investigations were done whenever required. The statistical analysis was performed by STATA 11.2 (College Station TX USA). Chi-square test has been used for the statistical evaluation.

\section{Results}

The present cross-sectional study was done to assess the clinical profile in microcephaly in children. The epidemiological data were summarised $\mathrm{n}$ the basis of the Performa filled by the parents. A total of 104 children were included in the study. Of the total 104 children were included, of them there were 72 males and 32 females. 
Males are more common as compared to females. The age range of children included in the study was from 6 months to 12 years. The mean age of the children was 5 years 9 months. The children were /divided into different groups as per age distribution.

Group A consist of children age less than 1 year, in group $B$ there were children between age 1-5 years, in group $C$ the age of children included was 5 to 10 years and in group $D$ the age of children was more than 10 years. There were 30 children with microcephaly in group A, in group B there were 52 children with microcephaly. For group $C$ there were 20 children with microcephaly and for group $D$ there were 2 children with microcephaly (Table 1 ).

Other clinical features with microcephaly observed as follows: Global developmental delay with microcephaly was seen in 88 , regression of milestones was observed in 16 cases, seizures with microcephaly was seen in 64 cases, microcephaly with intellectual disability was observed in 70 cases, cognitive defects like hearing impairment and visual impairment with microcephaly was seen in 56 children and 54 children respectively are found in the study (Table 2).

Table 1: Microcephaly distribution as per groups.

\begin{tabular}{|l|l|}
\hline \multicolumn{1}{|c|}{ Groups } & \multicolumn{1}{c|}{ Number of cases } \\
\hline Group A ( $<1$ year) & 30 \\
\hline Group B (1 -5 years) & 52 \\
\hline Group C (5 -10 years) & 20 \\
\hline Group D ( $>10$ years $)$ & 2 \\
\hline Total & 104 \\
\hline
\end{tabular}

Table 2: Clinical features present with microcephaly.

\begin{tabular}{|l|l|}
\hline \multicolumn{1}{|c|}{ Groups } & \multicolumn{1}{c|}{ Number of cases } \\
\hline Global Developmental Delay & 88 \\
\hline Regression Of Milestones & 32 \\
\hline Seizures & 64 \\
\hline Intellectual Disability & 70 \\
\hline Hearing Impairment & 56 \\
\hline Visual Impairment & 54 \\
\hline
\end{tabular}

\section{Discussion}

In the present study, the clinical features in correlation with the microcephaly were assessed in 104 patients. The current study has identified the prevalence of various underlying etiological causes for the disorder, majority of children presented with microcephaly had neurological symptoms in the
Form of intellectual disability was seen in 70 patients, Neurodevelopmental delay was seen in 88 children, seizures were observed in 64 children and associated other cognitive defects like vision were observed in 54 patients and hearing impairment was seen in 56 children, similar features have been explained in the study by Abdel Salman et al [10] who reported the overall prevalence of seizure in children with microcephaly was seen in $40.9 \%$.

The current study also shows that all the cases with congenital brain malformation had microcephaly since birth, clinically associated with hypertonia, hyperreflexia, GDD. This was similar to the study conducted by Herm Siegal and Poirer et al. As Zanelli et al have found there is a considerably high rate of morbidity and mortality due to perinatal asphyxia, which is still a major concern, as per his study $(21.8 \%)$ were diagnosed as HIE or cerebral palsy, which presented with microcephaly and had a significant postnatal history. These findings were similar to the study conducted by us $(25.5 \%)$.

Metabolic disorders are more likely to cause, the postnatal onset of microcephaly and typically associated with global developmental delay [11]. Prevalence of metabolic disorder with microcephaly in the present study was 2 that is for phenylketonuria, Elham et al have reported a total incidence of $(18.8 \%)$ in the study conducted reveal metabolic disorder as a cause of microcephaly, which was the largest number about other studies, among the metabolic disorder presented with microcephaly were phenylketonuria and methylmalonic aciduria [12].

\section{Conclusion}

Microcephaly is a frequent clinical sign which is common in many of the rare diseases, henceforth, an exact diagnosis is important for counseling the patient and the affected family, regarding the clinical course, possible complication, optimized medical support, and recurrent risk. Moreover, an exact diagnosis is also important for neuroprotective therapies for perinatal brain injuries.

\section{What does the study add to the existing knowledge}

Currently, available diagnostic tools (genetics) diagnosis, modern technologies that have still being optimized at the research level might provide a future diagnostic approach. 


\section{Author's contribution}

Dr. Gaurang Dilipkumar Pabani: Concept, study design

Dr. Rajeshri Rajendra Mehta: Manuscript preparation

Dr. Pramod Chandulal Shah: Manuscript preparation

\section{Reference}

01. COWIE V. The genetics and sub-classification of microcephaly. J Intellect Disab Res. $1960 ; 4(1) 42-47$.

doi: $10.1111 /$ j.1365-2788.1960.tb00751.x [Crossref]

02. Mitchell W. Neurological and developmental effects of HIV and AIDS in children and adolescents. Mental Retard Develop Disab Res Rev. 2001;7(3)211-216.

doi: $10.1002 / \mathrm{mrdd} .1029 \quad$ [Crossref]

03. Devakumar D, Bamford A, Ferreira MU, Broad J, Rosch RE, Groce N, Breuer J, Cardoso MA, Copp $A J$, Alexandre $P$, Rodrigues LC. Infectious causes of microcephaly- epidemiology, pathogenesis, diagnosis, and management. Lancet Infect Dis. 2018;18(1)e1-3.

doi: $10.1016 / S 1473-3099(17) 30398-5$ [Crossref]

04. Abuelo D. Microcephaly syndromes, In Seminars in pediatric neurology. WB Saunders. 2007 Sep 1 (Vol-14, No-3, pp-118-127).

doi: $10.1016 / j . s p e n .2007 .07 .003 \quad$ [Crossref]

05. D'Abate L. Contribution of Rare Copy Number Variants to the Development of Autism Spectrum Disorder in High-Risk Siblings (Doctoral dissertation).

Available at: [Article] [Crossref]

06. Passemard S, Kaindl AM, Verloes A. Microcephaly Handbook of clinical Neurology. Elsevier. 2013;pp-129-141.

doi: $\quad 10.1016 /$ B978-0-444-52891-9.00013-0

[Crossref]

07. Chimelli L, Avvad-Portari E. Congenital Zika virus infection- a neuropathological review. Child's Nervous System. 2018;34(1)95-99.

doi: 10.1007/s00381-017-3651-3 [Crossref]
08. Bevec D, Cavalli F, Cavalli V, Bacher G. Use of the human pancreatic polypeptide as a therapeutic agent. Google Patents. 2010. [Crossref]

09. Prasad K, Girimaji S, Manjunatha K, Khanna N, Rao B, Ravi V, et al. The etiologic patterns in microcephaly with mental retardation. Indian J Psychia. 1995;37(2): 70.

[Crossref]

10. Abdel-Salam GM, Halász AA, Czeizel AE. Association of epilepsy with different groups of microcephaly. Develop Med Child Neurol. 2000;42(11)760-777.

doi: $\quad 10.1017 / \mathrm{s} 0012162200001419 \quad$ [Crossref]

11. Shevell M, Ashwal S, Donley D, Flint J, Gingold $M$, Hirtz $D$, et al. Practice parameter evaluation of the child with global developmental delayreport of the Quality Standards Subcommittee of the American Academy of Neurology and The Practice Committee of the Child Neurology Society. Neurol. 2003;60(3)367-380.

doi: $\quad 10.1212 / 01 . w n l .0000031431 .81555 .16$ [Crossref]

12. Spilioti M, Evangeliou A, Tramma D, Theodoridou Z, Metaxas S, Michailidi E, et al. Evidence for treatable inborn errors of metabolism in a cohort of 187 Greek patients with autism spectrum disorder (ASD). Front Human Neurosci. $2013 ; 7 ; 858$. doi: $10.3389 /$ fnhum.2013.00858 [Crossref] 